\title{
Rating sputum cell quality in clinical trials for asthma and COPD treatment
}

This article was published in the following Dove Medical Press journal:

International Journal of COPD

\section{Frauke Pedersen ${ }^{1,2}$ \\ Ulrich M Zissler ${ }^{3}$ \\ Henrik Watz ${ }^{2}$ \\ Klaus F Rabe' \\ Jens $M$ Hohlfeld ${ }^{4,5}$ \\ Olaf Holz ${ }^{4}$}

'LungenClinic Grosshansdorf, Airway Research Center North (ARCN), German Center for Lung Research (DZL), Grosshansdorf, Germany; 2Pulmonary Research Institute at LungenClinic Grosshansdorf, Airway Research Center North (ARCN), German Center for Lung Research (DZL), Grosshansdorf, Germany; ${ }^{3}$ Center of Allergy \& Environment (ZAUM), Technical University of Munich and Helmholtz Center Munich, German Research Center for Environmental Health, Germany, Member of the German Center for Lung Research (DZL), Munich, Germany; ${ }^{4}$ Fraunhofer ITEM, Clinical Airway Research Biomedical Research in End-stage and Obstructive Lung Disease Hannover (BREATH), German Center for Lung Research (DZL), Hannover, Germany; ${ }^{5}$ Department of Respiratory Medicine, Hannover Medical School (MHH), Biomedical Research in End-stage and Obstructive Lung Disease Hannover (BREATH), Hannover, Germany

Correspondence: Frauke Pedersen Pulmonary Research Institute at LungenClinic Grosshansdorf, Airway Research Center North (ARCN), German Center for Lung Research (DZL), Woehrendamm 80, 22927

Grosshansdorf, Germany

Tel +49 4l02 60I 2416

Fax +49 4I02 888I II4

Email f.pedersen@pulmoresearch.de

\section{Background}

Induced sputum is a method to assess airway inflammation in clinical trials for asthma and COPD ${ }^{1-3}$ Sputum is a heterogeneous, viscous material containing inflammatory cell plugs, cellular debris, mucus, and saliva with squamous cells.

The quality of sputum cell preparations for differential cell count analysis depends on multiple factors and can be highly variable., ${ }^{4,5}$ Percentage of squamous cell contamination (SQ\%) is often used to assess the quality of sputum cell preparations. ${ }^{6}$ Here, we evaluated a comprehensive quality score, ${ }^{7}$ which also includes an assessment of the inflammatory cell morphology and amount of cellular debris.

\section{Methods}

A total of 30 sputum cell preparations from healthy subjects and patients with asthma or COPD were selected for a range of sample quality from studies from three German Center for Lung Research (DZL) sputum laboratories. The studies were approved by the respective ethics committees of University of Luebeck (AZ12-215), Marburg (AZ200/09), Munich (AZ5534/12), and Hannover (AZ5963), and written informed consent was obtained from all subjects. Sputum plugs were selected from saliva and processed with dithiothreitol as described. ${ }^{8}$ Nine experienced evaluators, blinded to the results of the others, counted 400 cells per sample and rated slide quality using a 5-point scale $(0,0.5,1,1.5,2$ - low to high; Figure 1$)$. This scale considers cell morphology, amount of cellular debris, and SQ\% only if it influences inflammatory cell identification. Interobserver variability (SD) and intraclass correlation coefficients (evaluators vs overall mean cell percentages) were computed. The data set was split into three quality levels based on the mean slide score (low: $<0.75$, intermediate: $0.75-1.25$, high: $>1.25)$.

\section{Results}

A total of 13 sputum cell preparations were rated as low quality, eight as intermediate quality, and nine as high quality. Five slides of a low quality had missing data for two to five evaluators and were excluded from the analysis. The overall mean (range) quality score was $1.1(0.4-1.6)$ with a mean SQ\% of $12 \%(1 \%-42 \%)$. Although the results were significant for each evaluator, we observed a correlation between slide quality score and SQ\%, with a wide range of $r$-values $(-0.39-0.69)$. The 17 slides of intermediate quality and high quality had a maximum SQ\% of $22 \%$, whereas four of eight slides from the low-quality group had $<22 \%$ squamous cells. Interobserver 

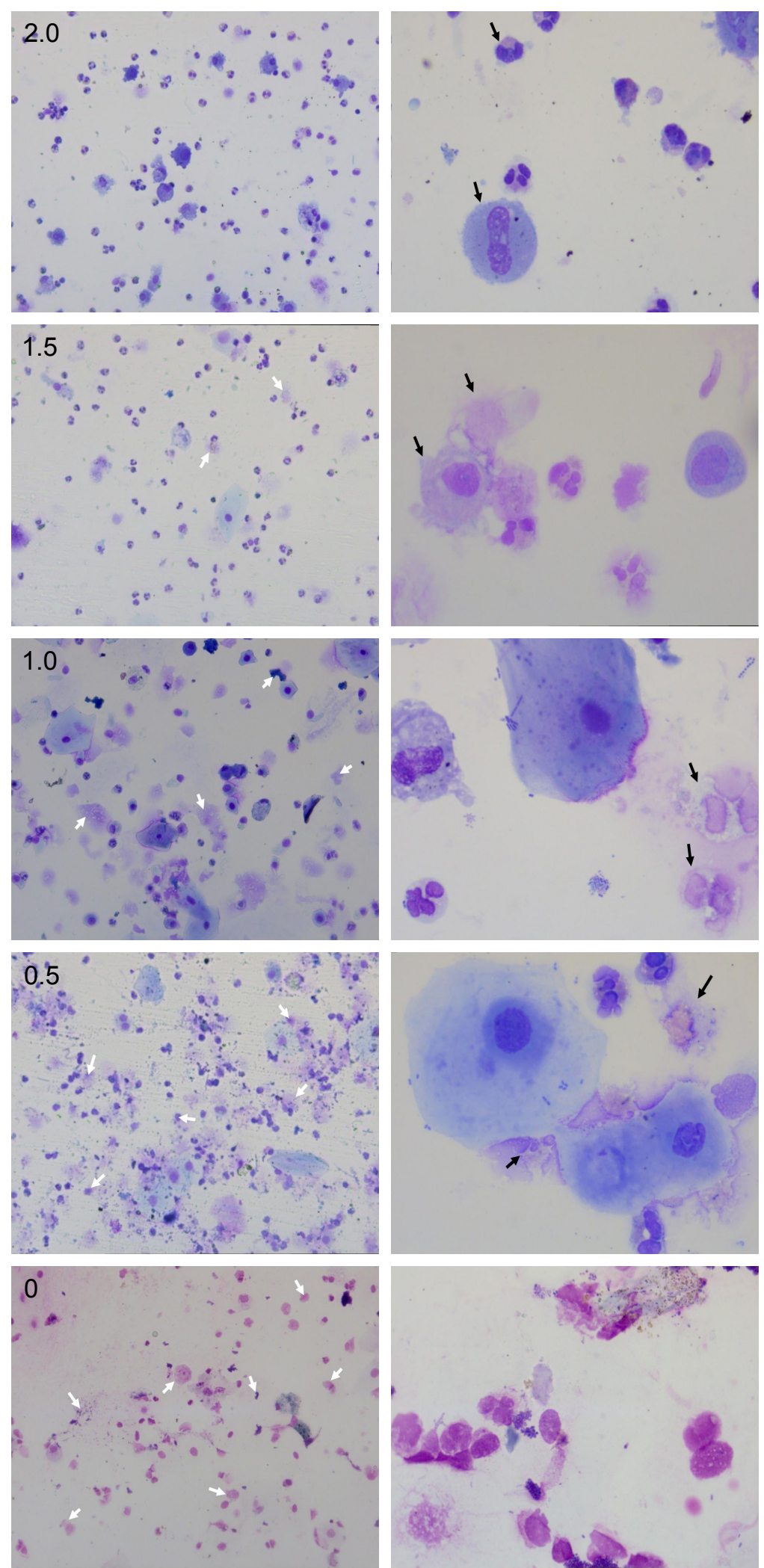

Figure I Comprehensive sputum slide quality score.

Notes: Representative examples of sputum cell preparations were rated on the 5-point scale. Original magnification, left column: $\times 200$; right column: $\times I, 000$. White arrows mark cellular debris; black arrows mark cellular integrity. Quality 2.0 - morphological quality of the cells: very good, differentiation of all cells possible, and no squamous epithelial cells present. Quality I.5 - morphological quality of the cells: good, differentiation of most cells possible, and few squamous epithelial cells present. Quality I.0 morphological quality of the cells: satisfactory, differentiation of many cells possible, and squamous epithelial cells present but with little or no effect on inflammatory cell identification. Quality 0.5 - morphological quality of the cells: borderline, differentiation of cells possible, high fraction of nonidentifiable cells, and many squamous epithelial cells present, which partially affect inflammatory cell identification. Quality 0.0 : cell detritus, less than 400 identifiable cells, or $>50 \%$ squamous epithelial cells present that clearly interfere with or prevent inflammatory cell identification. 

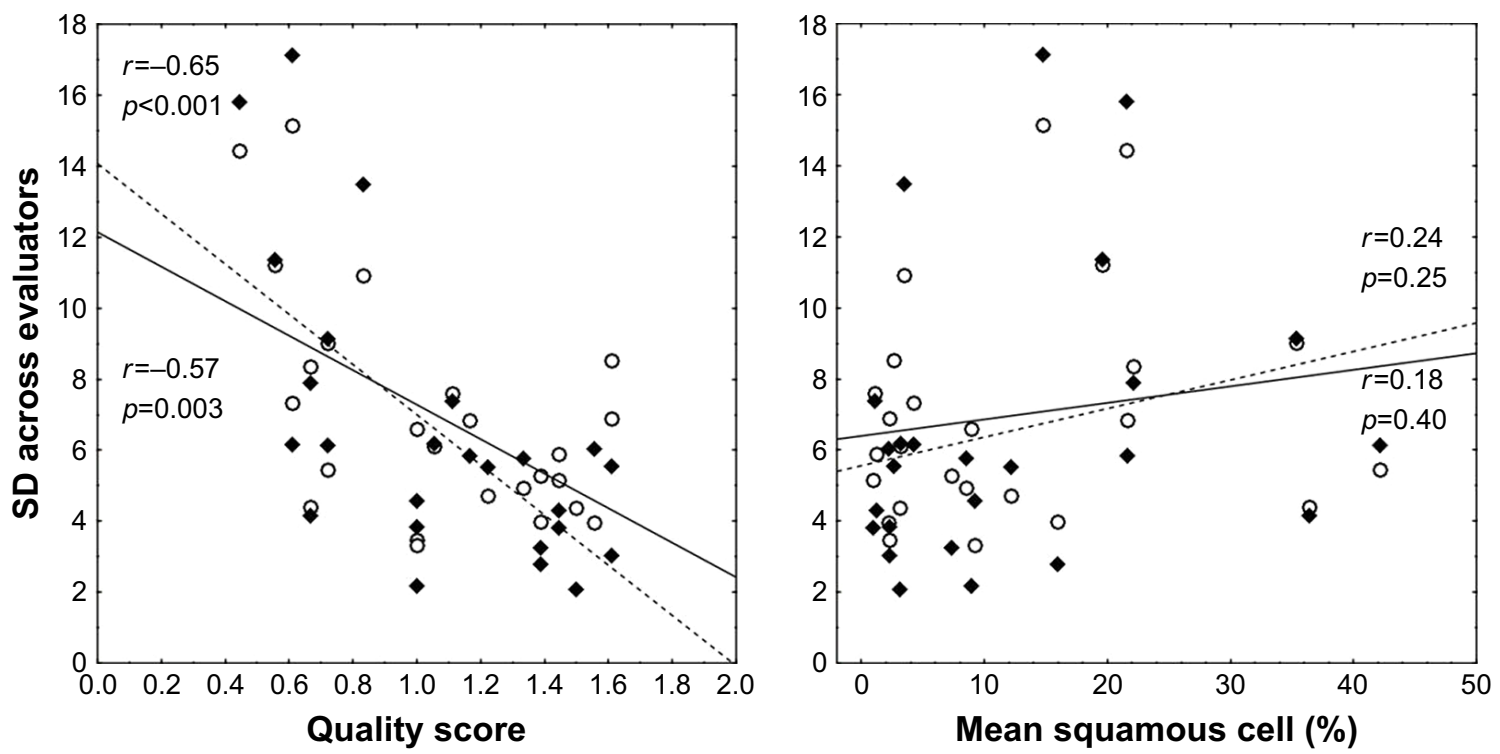

Figure 2 Correlation between quality score (low to high, $0-2$ ) and inter-evaluator variability (SD) for cell percentages across nine evaluators (left), and correlation between the mean level of squamous cells (\%) and SD (right).

Note: open circles, alveolar macrophages (AMs); closed diamonds, neutrophil granulocytes (NGs); closed lines, linear fit for AMs; dashed lines, linear fit for neutrophils; $r$, correlation coefficient.

variability for alveolar macrophages (AMs) and neutrophil granulocytes (NGs) did not correlate with SQ\% but did significantly correlate with the comprehensive quality score (Figure 2). For the samples with high quality and intermediate quality, the mean intraclass correlation coefficient for $\mathrm{AM}$ and NG was 0.97 and 0.98 , respectively, and for the samples with low quality, it was 0.77 and 0.80 , respectively.

\section{Discussion}

A proper selection of sputum plugs is important for obtaining high-quality sputum cell preparations. Nevertheless, we showed that the accuracy of differential cell counts also depends on inflammatory cell integrity and amount of cellular debris - criteria that are largely independent of $\mathrm{SQ} \%$. We agree with Sohani et $\mathrm{al}^{4}$ who suggested that sputum samples should not be excluded just for having a higher $\mathrm{SQ} \%$.

We focused on AM and NG only, because the number of samples with eosinophils was very low. Although eosinophils are more easily recognized in low-quality samples owing to their distinct staining, their percentages depend on a valid evaluation of AM and NG. In addition, a valid neutrophil count is important to estimate the inflammatory phenotype. $^{9}$

\section{Conclusion}

To judge sputum cell quality adequately and to define potential cutoffs for exclusion of sputum samples in clinical studies, we propose using a more comprehensive sputum slide quality score. We have demonstrated that excluding lowquality samples based on this score reduces inter-evaluator variability. The effect of excluding low-quality samples on the variability of biomarkers in sputum supernatants needs to be tested in further studies.

\section{Disclosure}

The authors report no conflicts of interest in this work.

\section{References}

1. Patel NR, Cunoosamy DM, Fagerås M, et al. The development of AZD7624 for prevention of exacerbations in COPD: a randomized controlled trial. Int J Chron Obstruct Pulmon Dis. 2018;13:1009-1019.

2. Pedersen F, Holz O, Kanniess F, et al. Longitudinal measurement of airway inflammation over one year in children and adults with intermittent asthma. BMC Res Notes. 2014;7:925.

3. Holz O, Biller H, Mueller M, et al. Efficacy and safety of inhaled calcium lactate PUR118 in the ozone challenge model-a clinical trial. $B M C$ Pharmacol Toxicol. 2015;16:21.

4. Sohani ZN, Strinich TX, Watson B, et al. Reproducibility of sputum differential cell counts is not affected by squamous epithelial cells. J Asthma. 2011;48(9):952-956.

5. Efthimiadis A, Spanevello A, Hamid Q, et al. Methods of sputum processing for cell counts, immunocytochemistry and in situ hybridisation. Eur Respir J Suppl. 2002;37:19s-23s.

6. Brightling CE, Monterio W, Green RH, et al. Induced sputum and other outcome measures in chronic obstructive pulmonary disease: safety and repeatability. Respir Med. 2001;95(12):999-1002.

7. Holz O, Mücke M, Zarza P, Loppow D, Jörres RA, Magnussen H. Freezing of homogenized sputum samples for intermittent storage. Clin Exp Allergy. 2001;31(8):1328-1331.

8. Pedersen F, Holz O, Lauer G, et al. Multi-analyte profiling of inflammatory mediators in COPD sputum - the effects of processing. Cytokine. 2015;71(2):401-404.

9. Wang F, He XY, Baines KJ, et al. Different inflammatory phenotypes in adults and children with acute asthma. Eur Respir J. 2011;38(3) $567-574$. 


\section{Publish your work in this journal}

The International Journal of COPD is an international, peer-reviewed journal of therapeutics and pharmacology focusing on concise rapid reporting of clinical studies and reviews in COPD. Special focus is given to the pathophysiological processes underlying the disease, intervention programs, patient focused education, and self management protocols.

This journal is indexed on PubMed Central, MedLine and CAS. The manuscript management system is completely online and includes a very quick and fair peer-review system, which is all easy to use. Visit http://www.dovepress.com/testimonials.php to read real quotes from published authors. 